\title{
Amorphous/crystalline silicon heterojunction solar cells with black silicon texture
}

\author{
Mathias Mews, ${ }^{1, \text { a) }}$ Caspar Leendertz, ${ }^{1}$ Michael Algasinger, ${ }^{2}$ Svetoslav Koynov, ${ }^{2}$ and Lars Korte ${ }^{1}$ \\ 1) Helmholtz-Zentrum Berlin, Institute of Silicon Photovoltaics, Kekuléstraße 5, D-12489 Berlin, \\ Germany \\ ${ }^{2)}$ Walter Schottky Institut, Technische Universität München, D-85748 Garching, \\ Germany
}

(Dated: 19 December 2017)

Excellent passivation of black silicon surfaces by thin amorphous silicon layers deposited with plasma enhanced chemical vapor deposition is demonstrated. Minority charge carrier lifetimes of 1.3 milliseconds, enabling an implied open circuit voltage of $714 \mathrm{mV}$, were achieved. The influence of amorphous silicon parasitic epitaxial growth and thickness, as well as of the texture depth is investigated. Furthermore quantum efficiency gains for wavelenghts above $600 \mathrm{~nm}$, as compared to random textured solar cells, are demonstrated in $17.2 \%$ efficient amorphous-crystalline silicon-heterojunction solar cells with black silicon texture.

\section{INTRODUCTION}

The random, high aspect ratio nanoscale surface texture, which is commonly called black silicon, has excellent anti-reflection and light scattering properties and its successful application on the front surface of solar cells has recently been shown ${ }^{1-3}$. The major challenge is the passivation of recombination active defects on the nanostructured and enlarged black silicon surface ${ }^{4}$. Previous works aiming at the application of black silicon in solar cells employ dielectric passivation layers ${ }^{1-3} \cdot \mathrm{AlO}_{x}$ layers deposited with atomic layer deposition for passivation of nanotextured silicon fabricated with reactive ion etching resulted in a few milliseconds minority carrier lifetime ${ }^{5}$ and $18.7 \%$ solar cell efficiency ${ }^{3}$. However, the alternative route of both passivation and contacting of black silicon with hydrogenated amorphous silicon (a-Si:H) has not been investigated. Hydrogenated amorphous silicon (a-Si:H) can provide excellent passivation of crystalline silicon surfaces and enables the electrical contacting of silicon wafers at the same time. Furthermore the use of amorphous-crystalline silicon heterojunctions (a-Si:H/c-Si-SHJ) is a proven concept for high-efficiency silicon solar cells ${ }^{6}$. The combination of the excellent optical properties of black silicon with the high quality surface passivation of amorphous silicon becomes even more interesting as the a-Si:H/c-Si-technology moves towards thinner wafers in order to realize even higher open circuit voltages $^{7}$.

\section{EXPERIMENTAL}

For the present study $280 \mu \mathrm{m}$ thick (100) and (111)

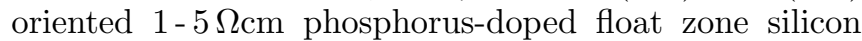
wafers were used as substrate material. Black silicon was fabricated by metal-assisted etching (MAE) of (100) Si

\footnotetext{
a) mathias.mews@helmholtz-berlin.de
}

wafers, as described in earlier work ${ }^{8}$. Only one sample surface was textured, while the other remained planar. The samples were stripped of their native oxide in $\mathrm{HF}$ $(5 \%)$. One nanometer of gold was evaporated, leading to isolated gold islands on the samples. Texture etching was carried out in a 1:5:20 solution of $\mathrm{HF}(50 \%)$, $\mathrm{H}_{2} \mathrm{O}_{2}(30 \%)$ and water at room temperature. For gold removal the samples were treated for 2 , or $4 \mathrm{~min}$ in iodine and potassium iodine solution $\left(\mathrm{I}_{2}: \mathrm{KI}: \mathrm{H}_{2} \mathrm{O}=1: 4: 40\right.$ weight ratio). A SC1 cleaning step was applied to remove nanoporous material ${ }^{9}$.

Prior to a-Si:H deposition the wafers were cleaned following the RCA procedure and dipped in diluted hydrofluoric acid (3 min, $1 \%$ ) to strip off the surface oxide. A-Si:H layers were deposited using plasma-enhanced chemical vapor deposition (PECVD). Intrinsic and doped layers were deposited at $0.5 \mathrm{mbar}$, with $60 \mathrm{MHz}$ excitation and a silane flow of $10 \mathrm{sccm}$. $2 \mathrm{sccm}$ diborane, or phosphine were added to deposit n- and p-type a-Si:H respectively. A hydrogen flow of 5 sccm was applied during the deposition of intrinsic layers. Doped layers were deposited using a plasma power density of $18 \mathrm{~mW} / \mathrm{cm}^{2}$ and $56 \mathrm{~mW} / \mathrm{cm}^{2}$ were applied for intrinsic layer deposition. The substrate temperature was $130^{\circ} \mathrm{C}$ for p-doped and intrinsic layers, but $195^{\circ} \mathrm{C}$ for $\mathrm{n}$-doped layers. The distance between electrode and substrate was $19 \mathrm{~mm}$ for intrinsic layers and $23 \mathrm{~mm}$ for doped layer deposition. Intrinsic layers ((i)a$\mathrm{Si}: \mathrm{H})$ were exposed to a hydrogen plasma treatment to decrease the interface defect density ${ }^{10}$. Process parameters of the hydrogen plasma treatments were $0.4 \mathrm{mbar}$, $130^{\circ} \mathrm{C}$ substrate temperature, a hydrogen flow of $20 \mathrm{sccm}$, $15 \mathrm{~mm}$ electrode to substrate distance and a power density of $112 \mathrm{~mW} / \mathrm{cm}^{2}$.

Indium tin oxide (ITO) layers were deposited using reactive radio frequency sputtering from an ITO target and $0.1 \%$ oxygen in the process gas flow. Metal contacts were fabricated by thermal evaporation. Front grids consist of a $10 \mathrm{~nm}$ titanium adhesion layer and $1.5 \mu \mathrm{m}$ of silver. $10 \mathrm{~nm}$ of titanium and $500 \mathrm{~nm}$ of silver constitute the full area back contacts. A photoconductance decay setup (Sinton Consulting WCT-100) was used for mi- 


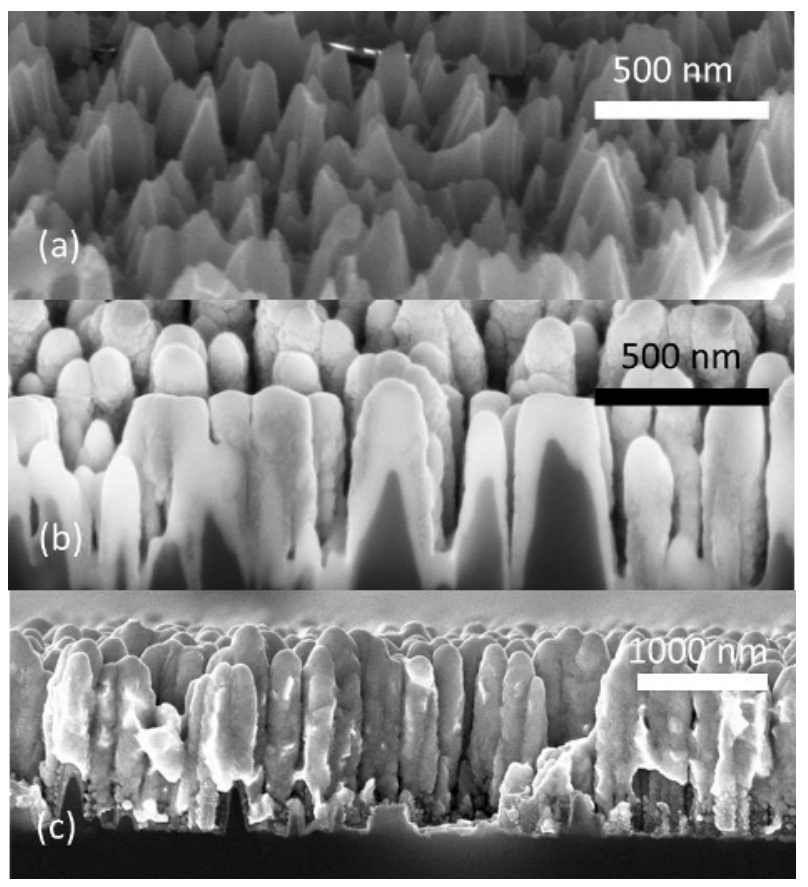

FIG. 1. SEM pictures of black silicon fabricated by $70 \mathrm{~s}$ of MAE and covered with $15 \mathrm{~nm}$ a-Si:H (a), $15 \mathrm{~nm}$ a-Si:H and $95 \mathrm{~nm}$ ITO (b) and a-Si:H, ITO and nominally $1.5 \mu \mathrm{m} \mathrm{Ag} \mathrm{(c).}$

nority carrier lifetime measurements ${ }^{11}$, a Hitachi S4100 with cold field emitter for Scanning electron microscopy (SEM) and a Perkin Elmer Lambda 19 spectrometer for optical measurements.

The effective reflectivity of the textured surfaces is calculated from 300 to $1200 \mathrm{~nm}$ using the ASTM G173 spectrum as irradiation.

\section{RESULTS AND DISCUSSION}

The black silicon surfaces exhibit an effective reflectivity of 3.3 to $4.7 \%$ in the range from 300 to $1200 \mathrm{~nm}$, compared to about $7 \%$ for an alkaline texture. The effective reflectivity value does not change after deposition of a-Si:H layers with deposition times of up to $60 \mathrm{~s}$ yielding a thickness of $30 \mathrm{~nm}$, since the amorphous silicon follows the contour of the nanotexture and has a refractive index similar to the one of crystalline silicon. Depositing ITO layers with a nominal thickness of 90 to $95 \mathrm{~nm}$ decreases the effective reflectivity to about 2.3 to $2.5 \%$. Because the refractive index of ITO lies between the refractive indexes of silicon and air. Therefore the grading of the reflective index between air and the silicon wafer ${ }^{12}$ already brought about by the black Si texture is further flattened out. SEM images of black silicon covered with a-Si:H (Fig. 1a) and with a-Si:H and ITO (Fig. 1b) are displayed. The roughly conformal coverage of the nanotexture with ITO is visible. The average texture height is in the range of $500 \mathrm{~nm}$.

One major challenge for passivation of a-Si:H/c-Si-HJs is

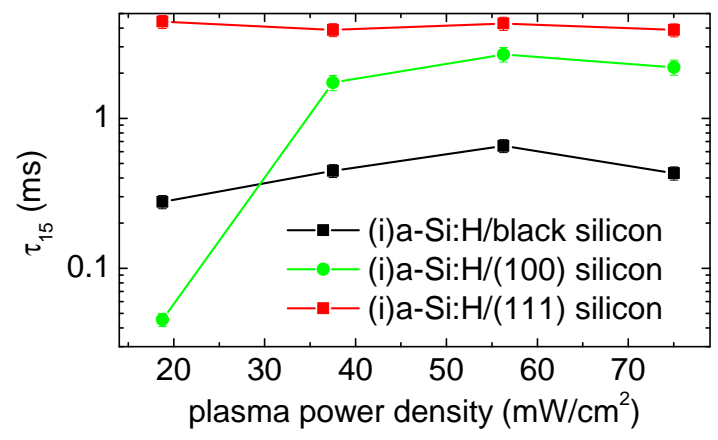

FIG. 2. Dependence of the minority charge carrier lifetime $\tau_{15}$ at an injection level of $10^{15} \mathrm{~cm}^{-3}$ on the plasma power density during intrinsic layer deposition. A post-deposition annealing step $\left(200^{\circ} \mathrm{C}, 20 \mathrm{~min}\right)$ was applied to these samples. Values for planar (100), planar (111) and black silicon surfaces (70 s MAE) are displayed. Lines are guides to the eye.

the preparation of passivation layers with high structural quality without parasitic epitaxial growth ${ }^{13}$. This is a severe restriction on (100)-surfaces, but far less problematic on $(111)^{13}$. As metal assisted etching (MAE) progresses preferentially along the $<100>$ direction $^{14}$ this could restrict the achievable passivation quality on black silicon. One parameter that allows to change from amorphous to epitaxial silicon growth is the plasma power density $^{15}$. By increasing the power density the deposition rate increases, reducing the structural quality of a-Si:H and thereby preventing epitaxial growth. Therefore the a-Si:H passivation quality on black silicon is explored as a function of the plasma power density. Furthermore the epitaxial growth has to be identified. It is known that thermal annealing at 200 to $300^{\circ} \mathrm{C}$ improves passivation of atomically sharp a-Si:H/c-Si-interfaces ${ }^{16}$, but leads to a degradation of the minority carrier lifetime for interfaces with partial epitaxial growth ${ }^{17}$. Therefore a post deposition annealing step at $200^{\circ} \mathrm{C}$ for 20 min was applied to discriminate between epitaxy free samples and those with partial epitaxy.

Minority carrier lifetime values for planar and nanotextured samples passivated with intrinsic a-Si:H deposited at varying plasma power densities are shown in Fig. 2. Intrinsic amorphous silicon deposition times of $30 \mathrm{~s}$, corresponding to film thicknesses of about $15 \mathrm{~nm}$, are chosen for planar (111) and (100) wafers, while deposition times of $60 \mathrm{~s}$ are chosen for black silicon to account for the higher aspect ratio. The planar back side of the black silicon samples is passivated with $4 \mathrm{~nm}$ intrinsic a-Si:H deposited at $56 \mathrm{~mW} / \mathrm{cm}^{2}$.

A change in the plasma power density from 36 to $18 \mathrm{~mW} / \mathrm{cm}^{2}$ results in a drop of the minority carrier lifetime on (100) Si by more than one order of magnitude. A similar, but less pronounced, lifetime decrease is visible for black silicon samples. In contrast, (111) samples do not experience any drop in lifetime in the depicted parameter range. Therefore it can be assumed that the 


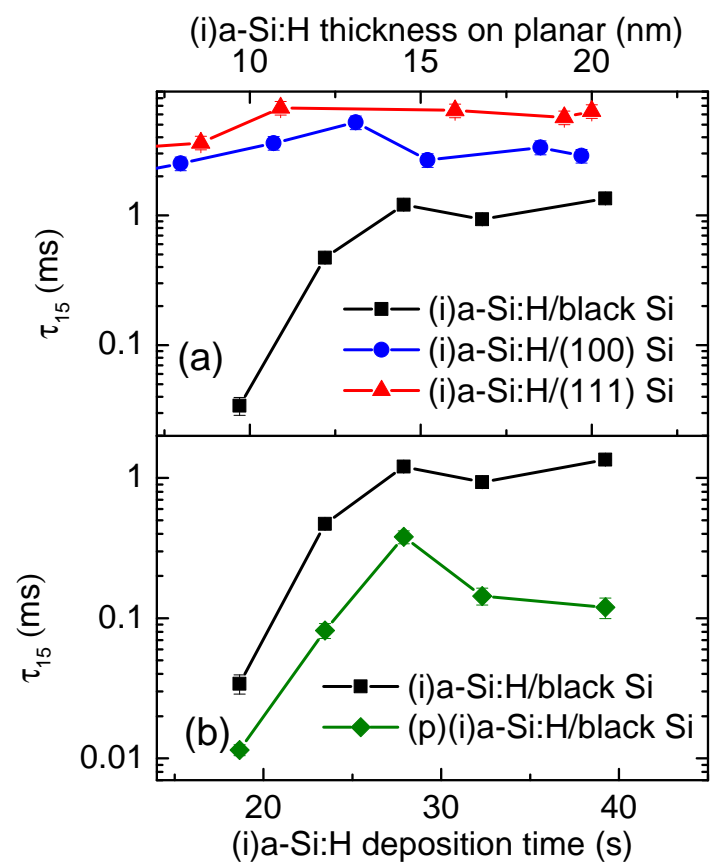

FIG. 3. Minority charge carrier lifetimes $\tau_{15}$ at an injection level of $10^{15} \mathrm{~cm}^{-3}$ (a) in dependence of the intrinsic passivation layer deposition time and thickness on planar wafers for (100), (111) and black silicon wafers. (b) black silicon with passivation layers and after the deposition of p-doped layers on the black silicon side and n-doped layers on the untextured side. Etch time for the black silicon samples was 70 s. Lines are guides to the eye.

black silicon surface possesses a similar tendency towards epitaxial growth as (100) silicon surfaces.

In a second parameter variation the amorphous silicon passivation layer thickness was varied on planar and on black-textured samples. The dependence of minority carrier lifetime on the passivation layer deposition time and thickness is shown in Fig. 3a. Due to the high aspect ratio a thicker amorphous silicon layer is needed for effective passivation of black silicon. While the passivation of planar wafers with amorphous silicon already reaches saturation at an amorphous silicon thickness of $10 \mathrm{~nm}$, the black silicon samples are most likely not even fully covered at this thickness and the passivation saturates only at about $15 \mathrm{~nm}$ film thickness. Furthermore the maximum lifetime is smaller for the black silicon surfaces, possibly due to the enlarged surface area and thus the higher total number of defects. The difference between (100) and (111) surfaces can be explained as being due to the higher density of dangling bonds on (100) surfaces compared to the (111) surface. The overall higher minority carrier lifetime of the black silicon samples in this second experiment are attributed to more thorough removal of gold residuals by prolonged etching (4 minutes).

The thickness value for which the minority charge carrier lifetime saturates can be used to deduce the surface increase due to the nanotexture as compared to a planar surface. Fujiwara and Kondo ${ }^{18}$ found that a-Si:H on a planar wafer changes from interface layer structural properties to bulk layer properties at a thickness of about $4 \mathrm{~nm}$. They also observed a saturation of open circuit voltage and thus lifetime at this thickness. The same saturation can be found for the nanotextured surfaces at about $15 \mathrm{~nm}$. This determines the surface increase due to the nanotexture to about a factor of 3.5 to 4 compared to a planar surface and is in agreement with experiments using SEM and atomic force microscopy ${ }^{9}$.

The best lifetime value achieved during these experiments is $1.3 \mathrm{~ms}$, enabling $714 \mathrm{mV}$ implied open circuit voltage. This high minority carrier lifetime has been achieved on fully nanotextured surfaces with an effective reflectivity of about $3 \%$ using a passivation layer with $15 \mathrm{~nm}$ nominal thickness.

The application of black silicon in a-Si:H/c-Si solar cells necessitates to form a $\mathrm{p} / \mathrm{n}$-junction and apply a backsurface field using doped a-Si:H layers. In Fig. 3b minority carrier lifetimes of black silicon samples with passivation layers and after deposition of n-type layers on the untextured side and p-type layers on the textured side are depicted. As can be seen in Fig. 3b, the lifetime values of all samples deteriorate drastically, corresponding to an implied $\mathrm{V}_{O C}$ decrease from 715 to $655 \mathrm{mV}$ for the sample with a $15 \mathrm{~nm}$ thick passivation layer. This effect is known from planar and alkaline textured a-Si:H/c-Si structures and is typically explained by Fermi level shift induced defect generation ${ }^{19}$. Still the degradation is stronger for the passivation layers on black silicon, as the planar reference only degrades from $730 \mathrm{mV}$ to $725 \mathrm{mV}$ implied $\mathrm{V}_{O C}$. Possible reasons are a different physical structure of the intrinsic amorphous silicon due to the growth on the black silicon surface, lateral inhomogeneous a-Si:H thicknesses, or gold residuals from the metal assisted etching process. Solar cells were fabricated using these samples and the IV characteristics and internal quantum efficiency (IQE) were measured. A strong decrease of the blue response for the black silicon solar cell as compared to a $\mathrm{KOH}$ textured reference is visible in Fig. 4.

One possible reason for decreased blue response is enhanced carrier recombination in a nanoporous region at the black etched surface ${ }^{20}$. A SC1 cleaning step is able to remove these nanoporous regions ${ }^{9}$ and was applied during the experiments presented here. Therefore parasitic absorption in nanoporous silicon can be excluded.

Another possible reason is parasitic absorption in amorphous silicon layers. To investigate whether this is the reason for the IQE decrease, the internal quantum efficiency of two solar cells with 70 s metal assisted etching time, but different intrinsic a-Si:H deposition times are shown in Fig. 4. Although there is a slight decrease of the IQE with increased a-Si:H thickness, it is obvious that this cannot be the reason for the strong blue deficiency of the nanotextured solar cells.

A third reason could be enhanced Auger recombination $^{1}$, or parasitic absorption in the nanotex- 


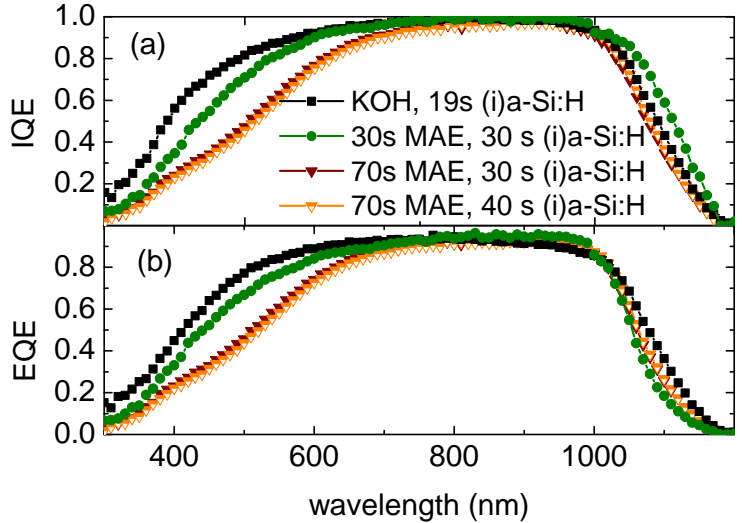

FIG. 4. (a) Internal quantum efficiency (IQE) of solar cells with $\mathrm{KOH}$ texture and $19 \mathrm{~s}$ intrinsic a-Si:H deposition time for the front side, compared to the IQE of solar cells with two black silicon texture times (70s and $30 \mathrm{~s}$ ) and two (i)a-Si:H deposition times $(30 \mathrm{~s}$, or $40 \mathrm{~s})$. P-type a-Si:H deposition time was $50 \mathrm{~s}$ for the black silicon texture and $15 \mathrm{~s}$ for the $\mathrm{KOH}$ texture. (b) External quantum efficiency (EQE) of the same devices.

ture. Therefore a solar cell with a $30 \mathrm{~s}$ long black silicon etch was fabricated, leading to a more shallow texture and an effective reflectivity of about $10 \%$. The IQE of this solar cell is also shown in Fig. 4a. For this solar cell only a slight decrease of the blue response is visible. Therefore the IQE decrease appears to be due to parasitic absorption, or enhanced recombination in the nanotexture. A possible reason for this parasitic absorption is that the p-type emitter surrounding the nanotexture enforces a majority carrier type inversion in the small structures. This could prevent the collection of minority carriers from this region.

The solar cell with $30 \mathrm{~s}$ MAE time has an efficiency of $17.2 \%$, a fill factor of $77.4 \%$, a short circuit current of $34.2 \mathrm{~mA}$ and an open circuit voltage of $649 \mathrm{mV}$. Thereby displaying better output parameters than the solar cell constructed on the $70 \mathrm{~s}$ texture, which has only $31.7 \mathrm{~mA}$ short circuit current, due to its lower blue response, an open circuit voltage of $604 \mathrm{mV}$ and a fill factor of $72.7 \%$. Leading to an efficiency of $13.9 \%$. Compared to a solar cell with random pyramid texture, a short circuit current of $36.2 \mathrm{~mA}$ and an efficiency of $20.2 \%$ the $30 \mathrm{~s}$ black silicon solar cell has an improved quantum efficiency for all wavelenghts higher than $700 \mathrm{~nm}$. Still the Fermi-level shift induced degradation of the passivation layers decreases the open circuit voltage well below the $707 \mathrm{mV}$, which were achieved applying the same deposition parameters on a planar (100) wafer.

\section{CONCLUSION}

It was shown that it is possible to passivate black silicon surfaces with a-Si:H. The passivation layer thick- ness has to be increased by at least a factor of three compared to planar surfaces to reach high quality passivation, which concurs with earlier measurements of the planar-to-textured surface ratio ${ }^{9}$. Furthermore investigations indicate, that black silicon surfaces exhibit a similar tendency towards epitaxial growth as (100) surfaces. Black silicon surfaces show great promise for the application in a-Si:H/c-Si solar cells since implied open circuit voltages of about $714 \mathrm{mV}$ have been reached for initial passivation layers, as well as excellent optical properties with reflectivities below $5 \%$. Amorphous-crystalline silicon heterojunction solar cells with black silicon front surface exhibiting a promising efficiency of $17.2 \%$ and gain in quantum efficiency compared to random pyramid textures for wavelengths above $600 \mathrm{~nm}$ have been fabricated.

\section{ACKNOWLEDGEMENT}

The authors would like to thank Kerstin Jacob and Mona Wittig for wafer cleaning, Carola Klimm for electron microscopy and Martin Stutzmann for fruitful discussions and critical reading of the manuscript. M.M., C.L. and S.K. acknowledge funding by the EU project NanoPV (FP7-NMP3-SL-2011-246331) and M.A. acknowledges funding by BMBF project NADNuM (03SF0402C).

${ }^{1}$ J. Oh, H. C. Yuan, and H. M. Branz, Nat. Nanotechnol. 7, 743748 (2012).

${ }^{2}$ W. C. Wang, C. W. Lin, H. J. Chen, C. W. Chang, J. J. Huang, M. J. Yang, B. Tjahjono, J. J. Huang, W. C. Hsu, and M. J. Chen, ACS Appl. Mater. Interfaces 5(19), 9752-9759 (2013).

${ }^{3}$ P. Repo, J. Benick, V. Vähänissi, J. Schön, G. von Gastrow, B. Steinhauser, M. C. Schubert, M. Hermle, and H. Savin, Energy Procedia 38, 866 - 871 (2013).

${ }^{4}$ P. Repo, J. Benick, G. v. Gastrow, V. Vähänissi, F. D. Heinz, J. Schön, M. C. Schubert, and H. Savin, Phys. Status Solidi RRL 7(11), 950-954 (2013).

${ }^{5}$ M. Otto, M. Kroll, T. Käsebier, R. Salzer, A. Tünnermann, and R. B. Wehrspohn, Appl. Phys. Lett. 100(19), 191603 (2012).

${ }^{6}$ M. Taguchi, A. Yano, S. Tohoda, K. Matsuyama, Y. Nakamura, T. Nishiwaki, K. Fujita, and E. Maruyama, IEEE J. Photovolt. 4(1), 96-99 (2014).

${ }^{7}$ T. Mishima, M. Taguchi, H. Sakata, and E. Maruyama, Sol. En. Mat. Sol. Cells 95(1), $18-21$ (2011).

${ }^{8}$ S. Koynov, M. S. Brandt, and M. Stutzmann, Appl. Phys. Lett. 88(20), 203107 (2006).

${ }^{9}$ M. Algasinger, J. Paye, F. Werner, J. Schmidt, M. S. Brandt, M. Stutzmann, and S. Koynov, Adv. Energy Mater. 3(8), 10681074 (2013).

${ }^{10}$ M. Mews, T. F. Schulze, N. Mingirulli, and L. Korte, Appl. Phys. Lett. 102, 122106 (2013).

${ }^{11}$ R. A. Sinton and A. Cuevas, Appl. Phys. Lett. 69, 2510-2512 (1996).

${ }^{12}$ M. Otto, M. Kroll, T. Käsebier, S. M. Lee, M. Putkonen, R. Salzer, P. T. Miclea, and R. B. Wehrspohn, Adv. Mater. 22(44), 5035-5038 (2010).

${ }^{13}$ U. K. Das, M.Z. Burrows, M. Lu, S. Bowden, and R. W. Birkmire, Appl. Phys. Lett. 92, 063504 (2008).

${ }^{14}$ Z. Huang, N. Geyer, P. Werner, J. de Boor, and U. Gsele, Adv. Mater. 23(2), 285-308 (2011).

${ }^{15}$ H. Fujiwara and M. Kondo, Appl. Phys. Lett. 90, 013503 (2007). 
${ }^{16}$ T. F. Schulze, H. N. Beushausen, T. Hansmann, L. Korte, and B. Rech, Appl. Phys. Lett. 95, 182108 (2009).

${ }^{17}$ T. Schulze, L. Korte, and B. Rech, Thin Solid Films 520, 4439 4444 (2012).

${ }^{18}$ H. Fujiwara and M. Kondo, J. Appl. Phys. 101, 054516 (2007).
${ }^{19}$ S. De Wolf and M. Kondo, J. Appl. Phys. 105(10), 103707 (2009). ${ }^{20}$ F. Toor, H. M. Branz, M. R. Page, K. M. Jones, and H. C. Yuan, Appl. Phys. Lett. 99(10), 103501 (2011). 